\title{
Refined Fault Detection Technique in Wireless Sensor Networks
}

\author{
S. Maheswari* and K. Arunesh \\ Department of Computer Science, Sri S. Ramasamy Naidu Memorial College, Sattur \\ 626203, Virudhunagar District, Tamilnadu, India
}

\begin{abstract}
Article Type: Article
Article Citation: Maheswaris, Arunesh K. Refined fault detection technique in wireless sensor networks. Indian Journal of Science and Technology. 2020; 13(06), 735-741.D01: 10.17485/ijst/2020/v013i06/000000

Received date: December 24, 2019

Accepted date: January 29, 2020

*Author for correspondence:

Maheswaris.Mmaheswaristr@ gmail.com 9 Department of Computer Science, Sri S. Ramasamy Naidu Memorial College, Sattur 626203, Virudhunagar District, Tamilnadu, India
\end{abstract}

\begin{abstract}
Background/objectives: Wireless sensor network (WSN) has sensor nodes; may failure happen because of hardware failure, communication error, energy depletion, and malicious attack. So there is a need to identify the problem and take necessary action to avoid performance degradation. The main objective of this research work is to enhance the performance and improves the network life time. Methods/statistical analysis: The proposed method discusses the faulty sensor node and the type of fault that may be transient, intermittent, and permanent compares it with the other network which has the same type of faulty node. It considers both the hard fault and soft fault and also it detects the fault easily. Findings: The fault node is identified from the neighbor using nodes and when the information is received from the exterior passed to the sink. Tables in this article show that the sensor which is detected has a permanent, transient, or intermittent fault in three WSNs with a common mode of fault. Novelty: The enhanced method saves the energy sources and finds the fault that occurs in common mode failure nodes in the WSNs.
\end{abstract}

Keywords: Wireless Sensor Network, Common Mode Failure (CMF), Fault Detection.

\section{Introduction}

A wireless network encounters physical or environmental conditions, that are temperature, noise, vibration, pressure motion in various locations [1]. A node may fail at any level of WNSs such as node, network and sink and cause of failure can be identified by detecting the fault in the sensor node [2]. Fault is any kind of defect or system in the network producing improper performance [3].

Common mode of failure (CMF) is that all nodes in the network may get corrupted for any reason. The node will be in two states always that is either "healthy" or "faulty" [4]. All nodes must involve themselves in detection because it reduces the need to send the data to central node [5]. Node will acknowledge its fault all the way through the data received from 
the neighbor with a threshold value [6]. Figure 1 describes the nodes with the common mode of failure nodes where the permanent fault occurred in the main sensor. Figure 2 explains the fault detection flow diagram. Figure 3 shows the transient fault that occurred in the main sensor among the CMF nodes. Figure 4 displays the permanent node where the node becomes fault while passing the data to the central node.

\section{Refined Fault Detection Technique}

This proposed method which considers both the hard fault and soft fault. If the node has the hard fault, it cannot communicate with its neighbor [7]. A soft fault node can communicate with altered behavior. The voting method assumes that each node has at least three neighbor using nodes. In Ref. [8], the proposed algorithm in which the sensor is identified as intermittent fault, transient fault, and permanent fault. The nodes which have three neighbors will be considered and the fault detected when the data passed to the central node over the periodic time. The steps that are involved in detection are as follows:

Step 1: Assign the total time of activation of nodes and possible data to be transferred within the time.

Step 2: Identify the sensors which have three neighbors.

Step 3: Exclude the node which does not have three neighbors.

Step 4: Search for the intermediate node.
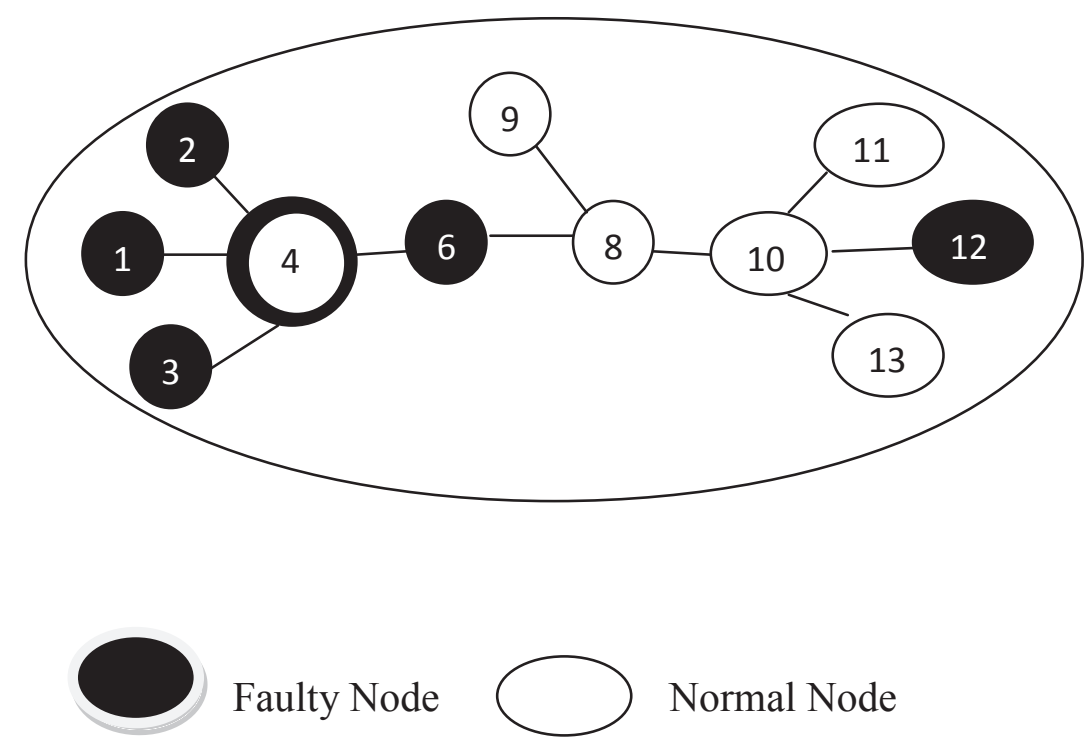


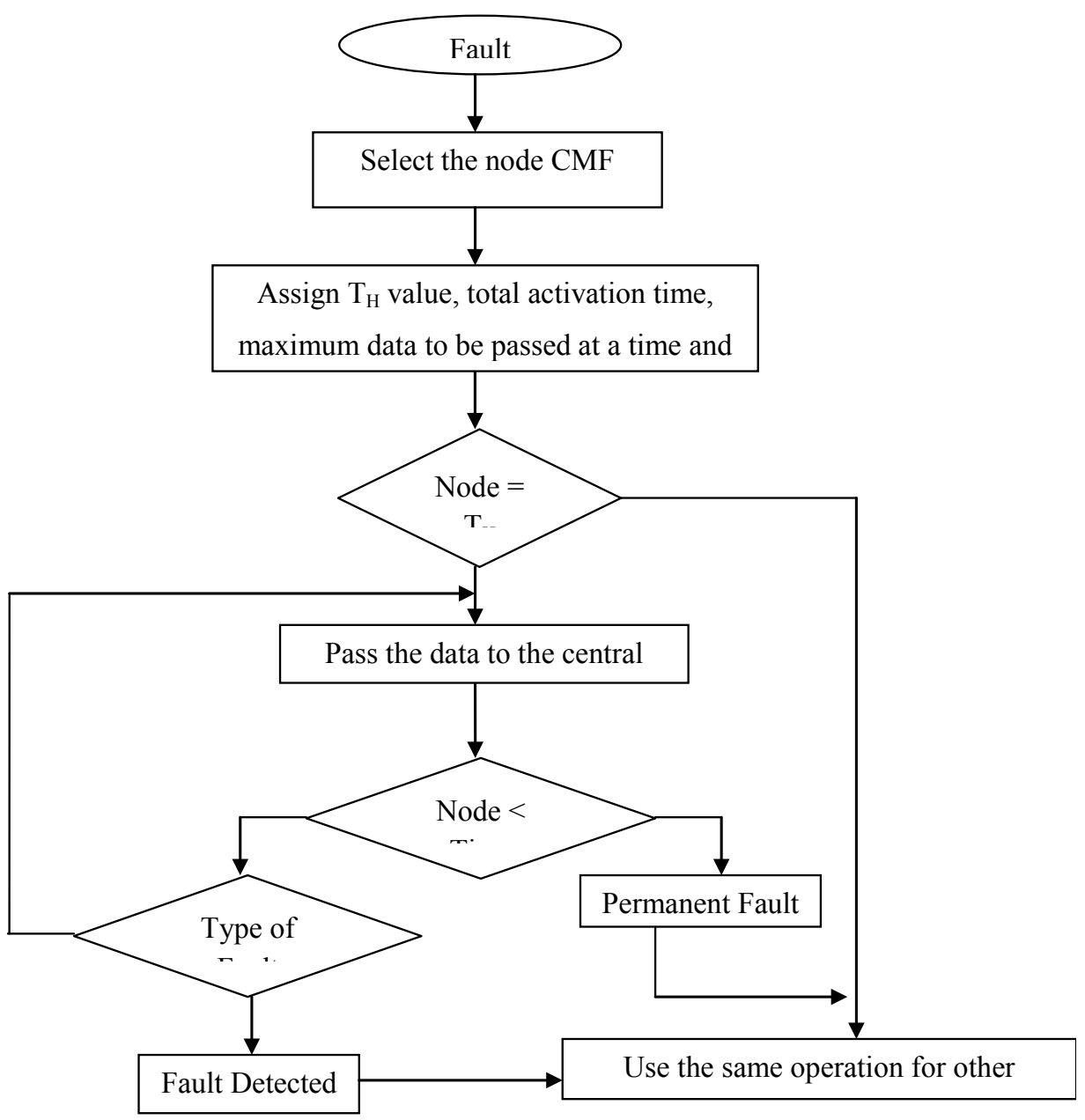

FIGURE 2. Fault detection block diagram.

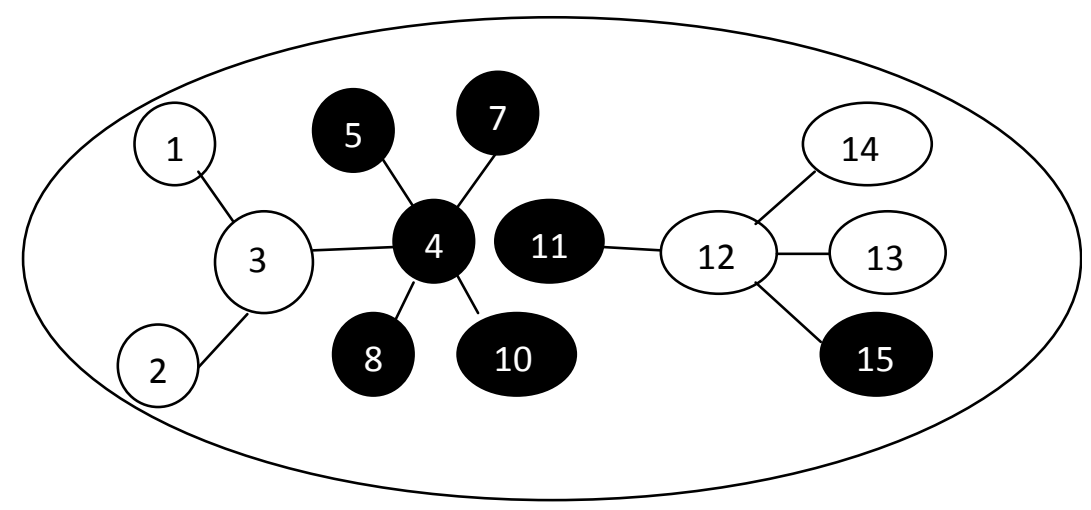

FIGURE 3. CMF with Transient/intermittent fault. 


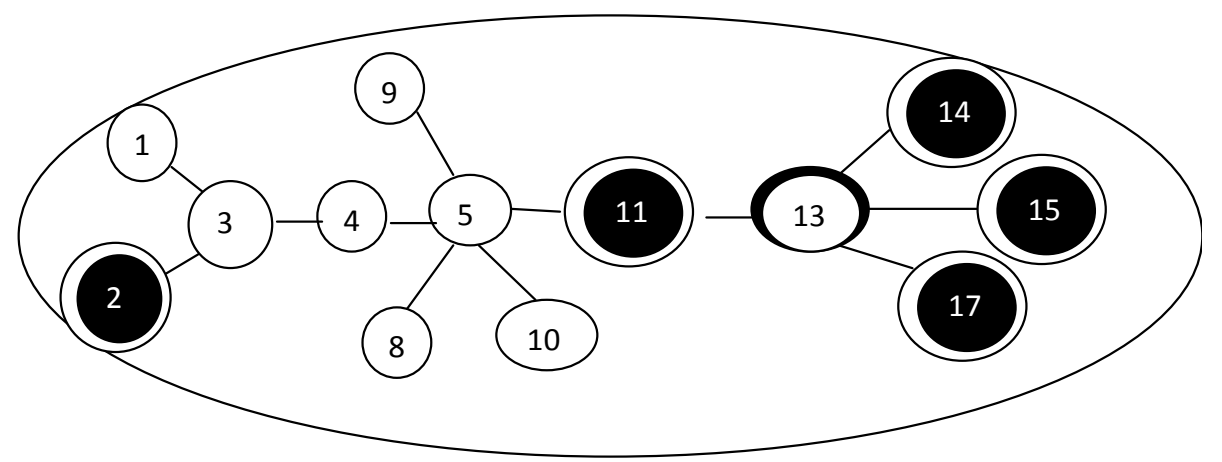

FIGURE 4. CMF with permanent fault.

Step 5: Pass the data to the central node.

Step 6: If not the data cannot be passed through neighbor the node is considered as at permanent fault.

Step 7: Else check for the node is intermittent or transient based on the node in time $\left(T_{\text {in }}\right)$ out time $\left(T_{\text {out }}\right)$ and the reactivation time.

Step 8: Check if the node is "good" or "bad".

Do this for each time for the common node and failure nodes. Take the network which has common failure and do this operation for the node and find out whether the fault is intermittent, transient, or permanent. Compare the network with the other one if the intermittent fault or transient fault occurred frequently [9]. If so, remove the node from the network in order to increase the lifetime of the network and save energy.

\section{Proposed Methodology}

\subsection{Proposed Algorithm}

\section{1st Phase:}

Declaration: $\mathrm{TH}=3$, $\mathrm{T}$ time $=5 \mathrm{~h}, \mathrm{R}$ act $=10 \mathrm{~S}$

$\mathrm{T}$ node $=\mathrm{n}$

for $(\mathrm{i}=1 ; \mathrm{i}<=\mathrm{n}-1 ; \mathrm{i}++)$

$\{$ If (i's neighbor length $>=\mathrm{TH}$ )

\{ If ( $\mathrm{i}==$ =black node")

$\mathrm{A}=+$ "i";

Else

$\mathrm{B}=+"$ "i"; $\}$

Print A. list and B.list;

$\mathrm{C}=$ merge (A. list, A. list .neighbour,

B.list, B.list.neighbour)

C. Ascending;

$\operatorname{Median}(\mathrm{C}) ;\}$

2nd Phase: 


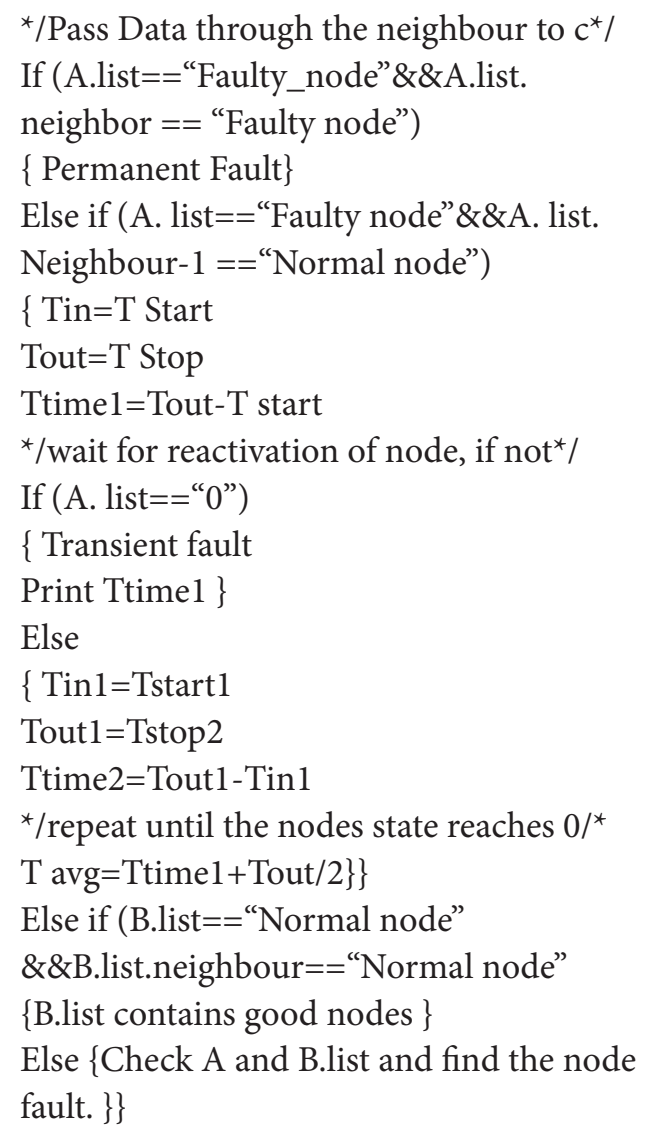

The algorithm will work well for the following networks also and the nodes which are involved in the fault detection are as good or bad thus the fault like permanent, transient and intermittent faults are also detected. At first, the status of each sensor is good and these sensors decide the neighbor as good or bad based on the data received from its neighbor.

In [10] the first phase of the algorithm, the sensors which have three neighbors are taken based on the voting method $T_{\mathrm{H}}$ Threshold value set for each sensor of neighbor Level $_{\mathrm{i}}$ Status of each sensor $T_{\text {time }}$ Total active time of each sensor $T_{\text {node }}$ Nodes involved in detection $R_{\text {act }}$ Reactivation Time mentioned above and the sensors which do not have three neighbors cannot take any decision except finding the status of the neighbor and in the next step, the sensor which comes into the $T_{\mathrm{H}}$ passes the data to the central node [11]. While passing the sensor is identified as fault senor (permanent, transient, intermittent) in terms of time $\left(T_{\text {in }}-T_{\text {out }}\right)$ taken to pass the data. Finally, each is sensor identified either as good or bad connected with its neighbor. The following example illustrates the algorithm which helps to find the fault (Tables 1-3).

\subsection{Proposed Algorithm Example}

In this example section, the two other Wireless Sensor Networks (WSNs) with CMF and the results of fault detection is discussed in the following figure. 
TABLE 1. Elements description

\begin{tabular}{ll}
\hline$T_{\mathrm{H}}$ & Threshold value set for each sensor of neighbor \\
Level $_{\mathrm{i}}$ & Status of each sensor \\
$T_{\text {time }}$ & Total active time of each sensor \\
$T_{\text {node }}$ & Nodes involved in detection \\
$R_{\text {act }}$ & Reactivation time \\
\hline
\end{tabular}

TABLE 2. Fault analysis

\begin{tabular}{llclll}
\hline $\boldsymbol{T}_{\text {node }}$ & Faulty NODE & Normal node & L1 & L2 & L3 \\
\hline 4 & $1,2,3,6$ & - & LG & FT & FT \\
8 & 9,10 & 6 & LG & GD & GD \\
10 & 12 & $8,11,13$ & LG & GD & GD \\
3 & 4 & 1,2 & LG & GD & GD \\
4 & $5,7,8,10,11$ & - & LG & LG & FT \\
13 & 15 & 12,14 & LG & GD & GD \\
3 & 1 & 4,2 & LG & GD & GD \\
5 & 11 & $4,9,8,10$ & LG & GD & GD \\
13 & 11 & $14,15,17$ & LG & FT & FT \\
\hline
\end{tabular}

TABLE 3. Fault analysis

\begin{tabular}{lcccc}
\hline Node & Total time (Hrs.) & $\left(\boldsymbol{T}_{\text {avg }}\right)$ & Data transfer & Fault type \\
\hline 4 & 5 & - & - & $\mathrm{PF}$ \\
4 & 5 & $15 \mathrm{~min}$ & $2 \mathrm{mb}$ & $\mathrm{TF}$ \\
13 & 5 & - & - & $\mathrm{PF}$ \\
\hline
\end{tabular}

\section{Conclusion}

This research comprises the type of fault in the common mode of failure nodes. The type of fault is detected whether permanent, or transient/intermittent when passing the received value to the neighbor nodes. The fault node is detected easily from a large number of faulty node. It increases the network life time.

\section{References}

1. Noshad Z, Javaid N, Saba T, Wadud Z, Qaiser Saleem M, Alzahrani ME, Sheta OE. Fault Detection in wireless sensor networks through the random forest classifier. Sensors. 2019, 19, 1568. DOI:10.3390/s19071568.

2. Shreenath KN. Fault detection mechanisms in wireless sensor networks-a review. International Journal of Scientific \& Technology Research. 2018, 7(3), 78-83. https://www.ijstr.org/final-print/ mar2018/Fault-Detection-Mechanisms-In-Wireless-Sensor-Networks-a-Review-.pdf

3. Krishnamachari B, Iyengar S. Distributed Bayesian algorithms for fault tolerant event region detection in wireless sensor networks. Proceedings of IEEE Transactions on Computers. 2004, 53(3), 241-250. DOI: 10.1109/TC.2004.1261832.

4. William S. Cryptography and network security principles and practices. 2006. https://books. google.co.in/books/about/Cryptography_and_Network_Security.html?id=sEwCT725lRgC 
5. Chen J, Kher S, Somani A. Distributed fault detection of wireless sensor networks. Dependability Issues in Wireless Adhoc Network and Sensor Network. 2006, 65-72. https://www.hindawi.com/ journals/wcmc/2018/4349795/

6. Babaie S. Distributed fault detection method and diagnosis of fault type in clustered wireless sensor networks. Life Science Journal. 2012, 9, 3410-3422. https://www.researchgate.net/ publication/276039918_Distributed_Fault_Detection_Method_and_Diagnosis_of_Fault_ Type_in_Clustered_Wireless_Sensor_Networks.

7. Mahapatroa, Khilar PM. Transient fault tolerant wireless sensor networks. Procedia Technology. 2012, 4, 97-101. https://www.sciencedirect.com/science/article/pii/S2212017312002927

8. Hajibegloo M, Javadi A. Fast fault detection in wireless sensor networks. In: Digital information and communication technology and its applications (DICTAP) second international conference. 2012; 62-66. https://ieeexplore.ieee.org/document/6215404

9. Shababbi M. Faulty sensor detection for wireless sensor networks. International Journal of Computer \& Information Technologies. 2013, 1 (3), 242-253. https://doi.org/10.1109/ CSE.2013.116

10. Siddiqua A. Distance based fault detection in wireless sensor network. International Journal on Computer Science Engineering. 2013, 5, 368-375. https://pdfs.semanticscholar.org/02d9/288f1b 5d6a8ef4ff190dbbb0021c76948535.pdf

11. Subhasri P, Padmapriya A. Security issues involved in sharing of healthcare information's through cloud storage. International Journal of Engineering and Technology. 2017, 9(5), 36363639. http://www.enggjournals.com/ijet/docs/IJET17-09-05-324.pdf 